\section{THE BIOLOGY WAR COMMITTEE}

$\mathrm{D}$

URING 1940 meetings were held at which the place of the biological sciences and the role of biologists in war-time were discussed by the British Ecological Society, the Association of Applied Biologists and the Society for Experimental Biology. As a result of these discussions each of the societies appointed a sub-committee to review the position and make further inquiries as to the nature of war problems. Early in 1941 the sub-committee of the societies agreed to form a joint committee and after several meetings formulated a number of proposals as to the best means of mobilizing both biologists and biological knowledge in the national interest.

In May, the Committee of the three societies was informed that the Agricultural Research Council jointly with the Department of Scientific and Industrial Research and the Medical Research Council had considered the proposals as to the application of biological knowledge to problems arising out of wartime conditions and the fuller use of the services of biologists during the War. They had, therefore, created a small Joint Committee to carry out "the declared policy of H.M. Government to make the fullest possible use of science to assist the Nation in its war activities" and to confer "on the further steps which might usefully be taken to carry this policy into effect so far as the biological sciences are concerned". The Joint Committee invited representatives of the Committee of the three societies, as being an organized body dealing with this matter, to meet them, and the following scheme was put before this Joint Committee.

It was proposed that, vis-d-vis the Joint Committee of the Government research organizations, the Committee of the three societies should be expanded into a larger committee representative of all the main aspects of biology and that this larger committee-the Biology War Committee-should cooperate with the Government Committee in the following ways :

(1) Act as a clearing-house through which problems or ideas coming from biologists can be brought to the notice of the Joint Committee of the Government and through it transmitted to the appropriate Government Councils or Departments.

(2) Provide a channel by which the Government can refer problems to biologists.

(3) Direct the attention of the Government to any results of current biological research which the Committee considers to be apposite to the war effort.

(4) Prepare reports or memoranda on any aspect of the War which is essentially biological or which has biological implications and to submit such reports to the Joint Committee of the Government research organizations.

In connexion with this scheme the Joint Committee of the Government research organizations wishes to stress that the proposed machinery is to supplement the existing contacts with biologists and in no way seeks to disturb the connexions already established. Heads of university departments, research institutes or research stations who are already in touch with the Department of Scientific and Industrial Research, the Medical Research Council or the Agricultural Research Council would, therefore, continue to communicate direct with the Council or Councils in regard to their recognized field or fields of investigation. Similarly, biologists who are undertaking specific investigations for Government Departments or the research organizations should continue to deal with the Department or Council concerned in regard to those researches in which they are already engaged. With these.provisos, the Government Joint Committee is most anxious that, to avoid undesirable complications, biologists shall submit all proposals or suggestions to the Government only through the Biology War Committee.

The original Committee of the three societies, in accordance with the suggestion put forward by the Joint Committee of the Government that the representation of the biological sciences should be as wide as possible, has given careful consideration as to how the original committee should be modified with a view to adequate representation of subjects. It was felt that, while the Committee should cover through its membership the main fields of biology, medicine should not be included, and that the representation should be weighted in favour of those fields which are not highly specialized and in which workers are not already closely linked with the three Government research organizations.

Members of the Committee of the three societies considered that, since at the outset, the work, scope and future of the Committee could not be foreseen, it would be unwise to limit the membership or to draw up a fixed constitution. They were of the opinion that the number of members should not be so great as to impede, especially under war-time conditions, both its efficiency and ability to make rapid decisions, but they also thought that while primarily the representation should be concerned with the main divisions of the biological sciences, yet there should also be some liaison with biological societies. After careful consideration the original committee co-opted fifteen additional biologists, expert in particular fields of biology. Afterwards the Committee approached the biological societies on the question of further liaison. The Committee suggested that, as a preliminary working mechanism for such liaison, biologists, under the exigencies of war-time and in view of the need for the Committee to function as soon as possible, would for the time being accept the arrangement that each biological society would nominate from the existing twenty-three members of the Committee a representative of the Society who would put before the Committee any views that the Society wishes to express and also report to the Society on the activities of the Committee; but here again it must be emphasized that the representation aimed at is that of subjects and not of societies as such.

It is clear that the whole question of the constitu. tion of the Biology War Committee and its relationship with biologists must involve considerable time and discussion with the societies. In view of the fact that a number of biological societies have already offered support to the scheme the Biology War Committee has decided that it should make this preliminary announcement of the formation of the Committee and its personnel to date. It would like again to stress that the composition and numbers are provisional, and it is envisaged that alterations or additions will be made as circumstances arise. The Committee is, so far, constituted as follows :

$\dagger *$ G. E. Blackman (secretary), Department of Botany, Imperial College of Science and Technology, London;

* Prof. W. B. Brierley, Department of Agricultural Botany, University of Reading ; 
$\dagger *$ Prof. P. A. Buxton (chairman), Department of Medical Entomology, London School of Hygiene;

Prof. H. G. Champion, Imperial Forestry Institute, Oxford ;

Prof. A. C. Chibnall, F.R.S., Department of Biochemistry, Imperial College of Science and Techno$\log$, London ;

Dr. E. M. Crowther, Chemistry Department, Rothamsted Experimental Station, Harpenden ;

Dr. C. Elton, Bureau of Animal Populations, University of Oxford ;

* Dr. W. P. K. Findlay, Forest Products Research Laboratory, Princes Risborough ;

$\dagger^{*}$ Dr. H. Godwin, Botany School, University of Cambridge ;

Dr. J. Hammond, F.R.S., Animal Nutrition Research Institute, Cambridge;

Prof. A. C. Hardy, F.R.S., Department of Biology and Oceanography, University College, Hull ;

Prof. J. S. Huxley, F.R.S., Zoological Society, London ;

$\dagger$ Dr. H. Martin, Long Ashton Research Station, Bristol ;

Dr. A. T. R. Mattick, National Institute for Research in Dairying, Shinfield, near Reading;

* Prof. J. W. Munro, Department of Zoology and Applied Entomology, Imperial College of Science and Technology, London;

Dr. J. Needham, F.R.S., School of Biochemistry, University of Cambridge;

Dr. C. F. Pantin, F.R.S. (vice-chairman), Department of Zoology, University of Cambridge;

* Dr. O. W. Richards, Department of Zoology and Applied Entomology, Imperial College of Science and Technology, London;

* Dr. M. A. H. Tincker, The Laboratories, Royal Horticultural Society, Wisley;

$\dagger *$ Dr. C. H. Waddington, Department of Zoology, University of Cambridge;

Dr. T. Wallace, Long Ashton Research Station, Bristol ;

Dr. E. B. Worthington, Freshwater Biological Association's Laboratory, Wray Castle ;

J. Z. Young, Department of Zoology, University of Oxford.

In conclusion, although the full Committee has only been in existence a short time, it has been very active. The Committee is inquiring into a number of suggestions and problems raised both by biologists and by the Government. These cover a surprising range of topies and many of its activities relate to confidential matters, in respect of some of which the Government has accepted the Committee's proposals.

Biologists who wish to put forward suggestions, proposals or problems under this scheme should communicate with G. E. Blackman, Hon. Secretary, Biology War Committee, Imperial College of Science and Technology, London, S.W.7, or with other members of the Committee. In this connexion it is pointed out that under the terms of reference all such suggestions are communicated to the Joint Committee of the Department of Scientific and Industrial Research, Medical Research Council and Agricultural Research Council which will, if necossary, refer them to the appropriate Government Departments for consideration. In the first instance all suggestions are couched in general terms and in an anonymous form.

* Members of the original joint committee of the Association of Applied Biologists, British Ecological Society and Society for Experimental Biology.

+ Members of Executive Committee.

\section{METEORITES AND THE AGE OF THE SOLAR SYSTEM}

\author{
BY W. J. ARROL, R. B. JACOBI \\ and PROF. F. A. PANETH
}

$\mathrm{B}$ ETWEEN the years 1928 and 1931 several papers on the age of iron meteorites were published, based on analyses of their helium and uranium content ${ }^{1}$. The last paper gave age values for twenty-two iron meteorites which were fairly evenly spread over periods ranging from 100 to 2,800 million years.

It was pointed out in this paper that the helium measurements were considered satisfactory, while the method used for the estimation of uranium still lacked in accuracy and was. to be replaced by an improved one $^{2}$. Owing to external cireumstances these experiments had to be abandoned after two years, and before final results could be achieved ${ }^{3}$. A new attempt to increase the accuracy of the age determinations was begun in 1937 in the Chemical Laboratories of the Imperial College of Science and Technology in London, and has been continued since 1939 in those of the University of Durham. Since general conditions a while ago again enforced an interruption, we propose to describe here briefly the main alterations made in the method, and the results so far obtained.

(1) The meteorite material used for each determination was increased to $15-20 \mathrm{gm}$. (2) The large quantities of hydrogen evolved by its dissolution in hydrochloric acid were burned with oxygen in a special device developed in connexion with another problem ${ }^{4}$. (3) Alternatively, the meteorite was dissolved, without evolution of hydrogen, in a reagent consisting of cupric and potassium chlorides and hydrochloric acid. (4) During this process sometimes not only the helium but also the radon liberated from the meteorite was collected and measured ${ }^{5}$. (5) After dissolution, the radium and thorium-X contained in the meteorite were precipitated, together with barium, as sulphates, and converted into chlorides. (6) The thoron and radon evolved from these chloride solutions were measured in an ionization ehamber connected with an electrometer valve ${ }^{6}$; the thoron immediately after preparation of the solution in a constant nitrogen stream, the radon after regeneration and transference into the chamber. (7) The $\alpha$-ray emission from the thoron and radon respectively was recorded photographically ${ }^{7}$ over periods of some twenty hours. (8) The radon measurement was repeated at least once after a few weeks time.

The combined effect of these various changes has considerably improved the accuracy of our activity measurements, as control experiments showed. If quantities of radium of the order of $1 \times 10^{-13} \mathrm{gm}$. (corresponding to an equilibrium amount of uranium of $3 \times 10^{-7} \mathrm{gm}$.) and of (aged) thorium salts of the order of $1 \times 10^{-6} \mathrm{gm}$. were added to the reagents, and the radium and thorium- $X$ precipitated and measured as described, the agreement was good within about 10 per cent. It was especially gratifying that it thus became possible for the first time to determine the thorium content of iron meteorites ${ }^{8}$; previously, it was not known to what extent the age values calculated on the basis of the helium and uranium contents only might be too high, but it now appears that consideration of the thorium has little influence on the result, least of all in the case of the oldest meteorites. 